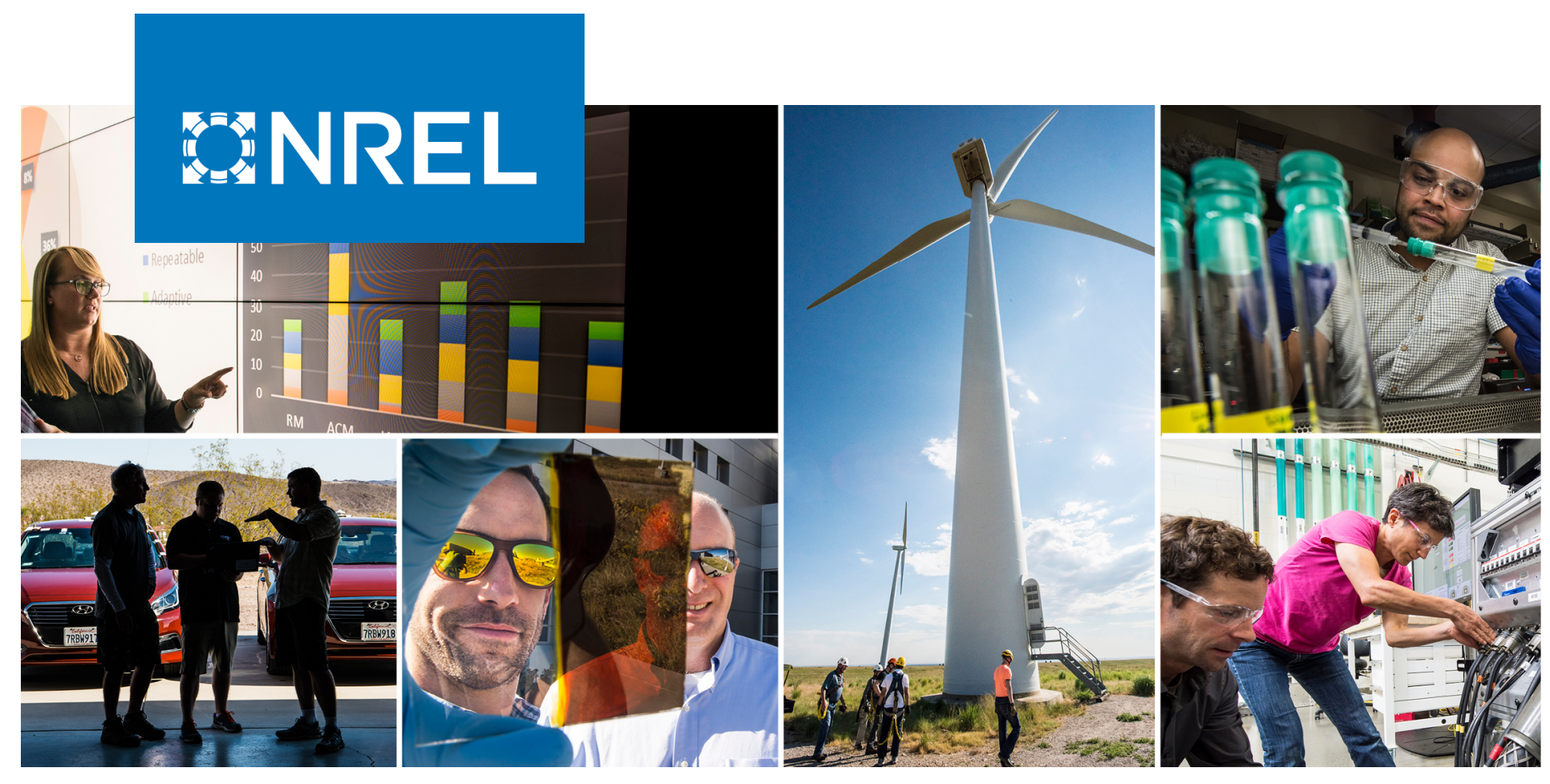

\title{
Advances in Coring Procedures of Silicon Photovoltaic Modules
}

\section{Preprint}

Helio Moutinho, Bobby To, Dana Sulas-Kern, ChunSheng Jiang, Mowafak Al-Jassim, and Steve Johnston

National Renewable Energy Laboratory

To be presented at the 47th IEEE Photovoltaic Specialists Conference (PVSC 47) June 15-August 21, 2020

NREL is a national laboratory of the U.S. Department of Energy Office of Energy Efficiency \& Renewable Energy

Operated by the Alliance for Sustainable Energy, LLC

This report is available at no cost from the National Renewable Energy Laboratory (NREL) at www.nrel.gov/publications.

\section{Conference Paper}

NREL/CP-5K00-76842

June 2020 


\title{
GNREL
}

\section{Advances in Coring Procedures of Silicon Photovoltaic Modules}

\section{Preprint}

\author{
Helio Moutinho, Bobby To, Dana Sulas-Kern, Chun- \\ Sheng Jiang, Mowafak Al-Jassim, and Steve Johnston \\ National Renewable Energy Laboratory
}

\section{Suggested Citation}

Moutinho, Helio, Bobby To, Dana Sulas-Kern, Chun-Sheng Jiang, Mowafak Al-Jassim, and Steve Johnston. 2020. Advances in Coring Procedures of Silicon Photovoltaic Modules: Preprint. Golden, CO: National Renewable Energy Laboratory. NREL/CP-5K0076842. https://www.nrel.gov/docs/fy20osti/76842.pdf.

NREL is a national laboratory of the U.S. Department of Energy Office of Energy Efficiency \& Renewable Energy Operated by the Alliance for Sustainable Energy, LLC

This report is available at no cost from the National Renewable Energy Laboratory (NREL) at www.nrel.gov/publications.

Contract No. DE-AC36-08GO28308
Conference Paper

NREL/CP-5K00-76842

June 2020

National Renewable Energy Laboratory 15013 Denver West Parkway Golden, CO 80401

303-275-3000 • www.nrel.gov 


\section{NOTICE}

This work was authored by the National Renewable Energy Laboratory, operated by Alliance for Sustainable Energy, LLC, for the U.S. Department of Energy (DOE) under Contract No. DE-AC36-08GO28308. Funding provided by U.S. Department of Energy Office of Energy Efficiency and Renewable Energy Solar Energy Technologies Office. The views expressed herein do not necessarily represent the views of the DOE or the U.S. Government. The U.S. Government retains and the publisher, by accepting the article for publication, acknowledges that the U.S. Government retains a nonexclusive, paid-up, irrevocable, worldwide license to publish or reproduce the published form of this work, or allow others to do so, for U.S. Government purposes.

This report is available at no cost from the National Renewable Energy Laboratory (NREL) at www.nrel.gov/publications.

U.S. Department of Energy (DOE) reports produced after 1991 and a growing number of pre-1991 documents are available free via www.OSTI.gov.

Cover Photos by Dennis Schroeder: (clockwise, left to right) NREL 51934, NREL 45897, NREL 42160, NREL 45891, NREL 48097, NREL 46526.

NREL prints on paper that contains recycled content. 


\section{Advances in Coring Procedures of Silicon Photovoltaic Modules}

\author{
Helio Moutinho \\ National Renewable Energy \\ Laboratory \\ Golden, USA \\ helio.moutinho@nrel.gov
}

\author{
Bobby To \\ National Renewable Energy \\ Laboratory \\ Golden, USA \\ bobby.to@nrel.gov \\ Mowafak Al-Jassim \\ National Renewable Energy \\ Laboratory \\ Golden, USA \\ mowafak.aljassim@nrel.gov
}

\author{
Dana Sulas-Kern \\ National Renewable Energy \\ Laboratory \\ Golden, USA \\ dana.sulas@nrel.gov \\ Steve Johnston \\ National Renewable Energy \\ Laboratory \\ Golden, USA \\ steve.johnston@nrel.gov
}

\author{
Chun-Sheng Jiang \\ National Renewable Energy \\ Laboratory \\ Golden, USA \\ chun.sheng.jiang@nrel.gov
}

\begin{abstract}
We describe advances on procedures used for the coring of silicon photovoltaic modules. These procedures involve coring specific locations, starting from the back of the modules, and removing selected parts of the cell structure, while preserving the front tempered glass. The standard coring procedures had to be modified from case to case due to the different cell structures and measurement requirements. We provide examples of the characterization of the cored samples by scanning electron microscopy and energy-dispersive $X$-ray spectroscopy. Finally, we describe a simple process to create small openings at specific locations on the back of photovoltaic modules to allow for efficiency-related measurement of individual cells and groups of cells.
\end{abstract}

Keywords—coring, silicon, photovoltaic modules.

\section{INTRODUCTION}

The progress in solar cell fabrication in the last decades has resulted in increased efficiencies, higher stability, and lower prices. Consequently, photovoltaic (PV) technology has gained significant ground in relation to other types of energyproduction methods. Nowadays, depending on the specific application, the use of PV modules may be economically viable. Furthermore, with the increase in the effects of global warming, PV technology has become a major source of alternative energy to reduce the emission of greenhouse gases.

Because of the exponential increase in the number of PV module installations, several areas are receiving increased interest, such as: batteries, needed for the storage of the energy generated by the PV modules in many applications; soiling mitigation, to minimize the negative effects of weather on the performance of PV modules; and reliability, to guarantee that PV modules will provide satisfactory performance for many decades. However, most studies on reliability are limited and mostly focus on the degradation of parameters related to efficiency and power output. Currently, there is very little study on the relation between these parameters and microscopic parameters such as composition or defect structure, which would provide insight on how to produce more efficient, reliable, and durable PV modules.
This task is very important for improving the performance and reliability of the next generation of photovoltaics.

To make the connection between macroscopic and microscopic parameters, we must develop techniques to remove small specific areas of PV modules, without damaging them, that can be analyzed by techniques such as scanning electron microscopy (SEM), scanning probe microscopy (SPM), and more. Developing this technology is of prime importance for the task above. Unfortunately, there is very limited literature on this subject, and we had to develop several techniques to core small areas from PV modules without affecting the properties of the solar cell material. These techniques have been described in previous publications [1,2]. Furthermore, because of the different kinds of module structure and measurement requirements, no procedure exists that works for every module. In this work, we present advances on the coring techniques that allowed us to 1) avoid damaging the thin back-contact layer on cored HIT Si modules, 2) core Si modules for the study of cracks, and 3) open connection areas for measuring individual cells and groups of cells in PV modules.

\section{EXPERIMENTAL PROCEDURE}

We previously developed two different coring procedures: full and partial coring $[1,2]$. In full coring, small pieces of the module are removed from pre-selected areas using a special drill and diamond-embedded bits. Because most PV modules use tempered glass on the front, this procedure results in breakage of the whole module, and we want to avoid that whenever possible. In partial coring, we core from the back side of the module and stop just before we reach the tempered glass so as to avoid breaking it. Here is a simplified description of the partial coring procedure for a standard Si module:

- Select and mark areas to be cored.

- Mechanically remove the Tedlar polyester Tedlar (TPT) and ethylene vinyl acetate (EVA) layers from the back of the Si module on areas to be cored using a Dremel tool, avoiding any significant increase in temperature. 
- Partially core the back of the module (until the front EVA layer is reached) using a $1 / 2$ " or $3 / 4$ " coring bit and coolant/lubricant.

- Attach metallic posts to the cored areas using acetonesoluble adhesive.

- Wait several hours for the adhesive to cure.

- Remove the posts from the module using an open-end wrench. The solar cell separates from the module on the interface with the front EVA.

- Immerse posts with Si solar cell in acetone for about a day.

- Remove Si samples from metallic posts.

For cross-section analysis, several samples were encapsulated between two pieces of high-conductivity silicon using Ag-conductive epoxy (EPO-TEK H20E) and polished in a MultiPrep mechanical polisher (Allied High Tech Products), using diamond-lapping-film pads with different grits.

Samples produced in this work were analyzed by SEM and energy-dispersive X-ray spectroscopy (EDS) in a Hitachi 4800 FEG SEM and Thermo Scientific UltraDry EDS detector, respectively.

\section{RESULTS AND DISCUSSION}

\section{Si HIT MODULES}

We applied the partial coring procedure on two HIT modules, one kept in dark and one deployed in the field for 10 years, to study the causes of degradation. The structure of the modules is seen in Fig. 1. The standard Si modules in which we previously applied our coring procedure have a relatively thick continuous Al layer as part of the back contact, and mechanically removing the back TPT and EVA is relatively easy. In contrast, the HIT modules use a very thin layer of indium tin oxide (ITO) and thin Ag fingers. Removing the TPT and EVA without affecting the back contact posed a challenge for coring. Furthermore, the degradation of these modules was

\begin{tabular}{|c|}
\hline Glass \\
\hline EVA \\
\hline ITO ( 100 nm) \\
\hline p-type a-Si:H $(\sim 10 \mathrm{~nm})$ \\
\hline Intrinsic a-Si:H $(\sim 10 \mathrm{~nm})$ \\
\hline n-type c-Si:H ( 160 $\mu \mathrm{m})$ \\
\hline Intrinsic a-Si:H ( 10 nm) \\
\hline n-type a-Si:H ( 10 $\mathrm{nm})$ \\
\hline ITO ( 100 nm) \\
\hline EVA \\
\hline Backsheet \\
\hline
\end{tabular}

Fig. 1. Structure of the cored HIT modules.

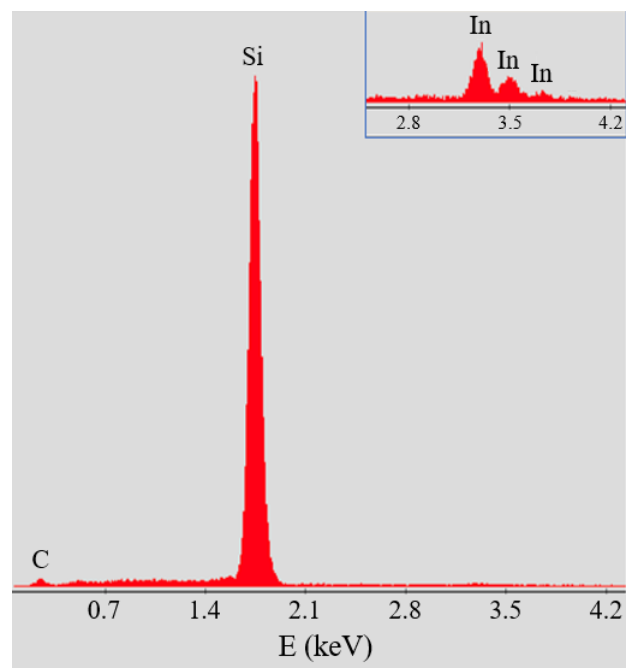

Fig. 2. EDS analysis of the back of the cored cell showing that the ITO layer was removed during the mechanical removal of TPT and EVA. The inset (top right) shows the In peaks of the ITO layer on the front of the cored cell.

possibly caused by deterioration of the ITO, which made it more important to preserve this layer during coring.

We started by applying the standard procedure, and there was not enough precision to remove the TPT and EVA while preserving the $\mathrm{Ag}$ lines, as was visually clear. Further EDS analysis (Fig. 2) showed that the thin ITO layer was also removed during this process, as well as part of the Si on the back. Preserving a thin layer of about $100 \mathrm{~nm}$ is very difficult, and most of our attempts - such as applying temperature to soften the EVA layerfailed because they require applying hundreds of degrees to the solar cell material, which could induce changes, such as diffusion of impurities. After many experiments, we were able to develop two new coring methods that preserved the back ITO layer.

The first method required designing and fabricating much thinner metallic stubs that could fit into the chamber of analytical equipment, such as an SEM. Initially, we cored the module until we just touched the back EVA, on a larger area than desired for the final cored sample (Fig. 3); then we applied a large-diameter stub (1") with adhesive directly onto the TPT.

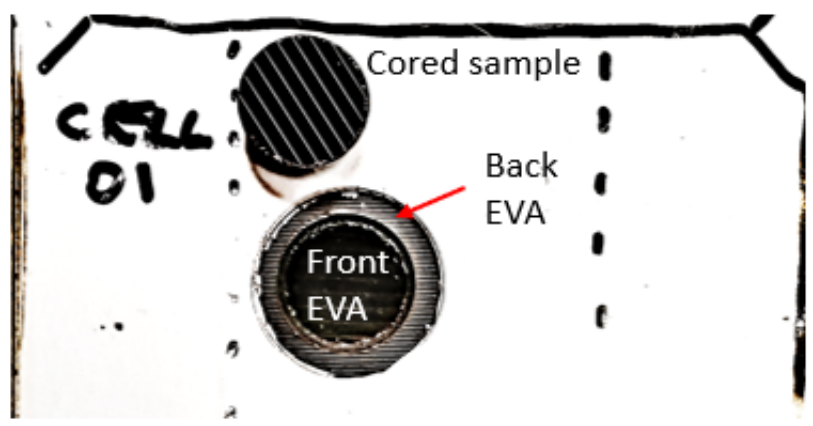

Fig. 3. Back of a cored HIT module showing the initial larger cored area, with the back EVA still in the module; the cored area, with the front EVA at the center; and the cored sample. 
With an open-ended wrench, we were able to remove the TPT, leaving just the back EVA on the module. After that, we cored inside that area with a $3 / 4$ "-diameter drill until we reached the glass, and then we applied the thin metallic stub with adhesive. After curing, we used the open-end wrench to remove the cored sample from the module, as observed in Fig. 3. SEM and EDS analyses showed that the whole sample was cored, but this method produces samples that cannot be easily removed from the metallic stub. This is not an issue for analytical techniques that can examine deep into the material, such as secondary-ion mass spectrometry, which has a depth resolution of up to $\sim 2 \mathrm{~nm}$ [3]. However, it does not allow for the analysis of the cross section of the sample, unless special methods such as beveling are used for sample preparation.

The second coring method allowed for the easy analysis of cross sections and was also developed for analytical techniques that require access to the back contact, such as several different SPM measurements. In this case, we noticed that for this type of module, we were able to carefully peel off the TPT and back EVA using tweezers. This is a delicate process, but after practicing for some time, we were able to consistently remove the back material of the HIT modules while preserving the Ag fingers and ITO, as demonstrated in SEM and EDS analyses. After this, the module was cored using the standard procedure with excellent results.

EDS and SEM analyses on the back of these samples confirmed that both the back $\mathrm{Al}$ gridlines and ITO were still in the sample after coring using this method.

We were able to core samples from both modules, which are currently being analyzed by many different analytical techniques. Several of these samples were used in one paper that will be presented in this meeting [4].

\section{INVESTIGATION OF SOLDER IN Si PV MODULES}

In this study, our interest was in investigating the solder in Si modules deployed in the field for several years. These modules showed strong fill factor degradation that was associated with an increase in series resistance [5]. The objective was to investigate the existence of cracks in the solder and/or the formation of different compounds on the Ag contact.

Coring of the solder region presented a particular challenge because of the difference in height between the Al back contact and

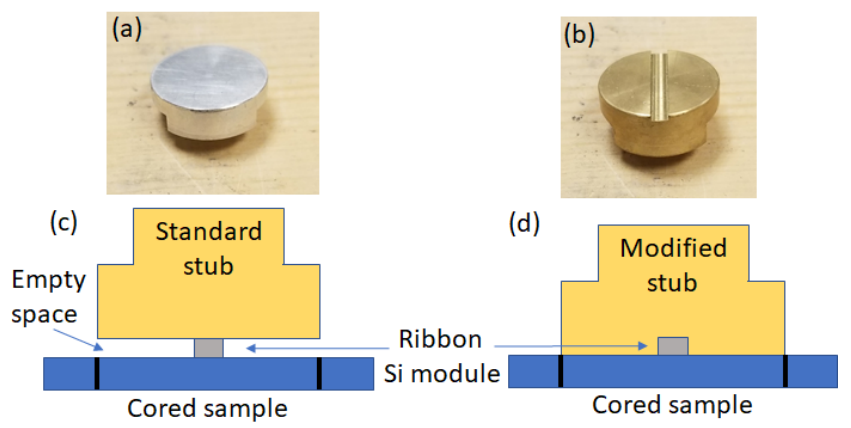

Fig. 4. (a)(b) Standard sample holder and new design, respectively; (c)(d) Configuration of the standard and new setup for stub attachment to the sample, respectively. the ribbon on the back of the PV module. In the standard procedure, when we need to core an area around a ribbon, we simply remove it to make the area flat. Applying the standard procedure without removing the ribbon did not work because after coring, there was a gap between the bottom of the metallic stub and the back contact that was too large to be filled by the adhesive, as observed in Figs. 4(a) and 4(c). The solution for this problem was to design a special metallic stub (Fig. 4b) with a groove to accommodate the ribbon and eliminate the empty space (Fig. 4d).

Coring was performed following the standard procedure. However, many of the front ribbons detached from the cored samples during removal from the module, as observed in Fig. 5(a). Probably, the thick, relatively low-speed coring drill did not completely cut the ductile $\mathrm{Cu}$ ribbon in the front of the module, and the $\mathrm{Cu}$ ribbon on the cored sample was pulled out by the part of the ribbon that stayed on the module during the sample removal step. Because the module uses tempered glass, a single cut will result in the whole module breaking in thousands of small pieces [6]. To prevent this from happening, we stop coring as soon as the tempered glass is reached-which, in this case, was not enough to completely cut the front $\mathrm{Cu}$ ribbon.

The solution for this problem was to use a small, thin, highspeed rotating saw to cut the module from the top of the back $\mathrm{Cu}$ ribbon down to the front $\mathrm{Cu}$ ribbon on the exact locations where the coring drill was going to cut the ribbons. The rotating saw was stopped as soon as the front EVA was reached and before it could cut the glass. These cuts are observed in Fig. 5 (b) from the back of the module. The ribbon is soldered to the back of the module in three places only, and part of it detached from the module after the cuts, as observed in the figure. With the front ribbon cut at the coring position, we resolved the delamination issue.

After these adjustments, and the new metallic stub, we were able to successfully and repeatedly core the module, as observed in Fig. 5(c), which shows a cored area on the module, with the front EVA, and the cored solar cell, with the front ribbon still attached to it.
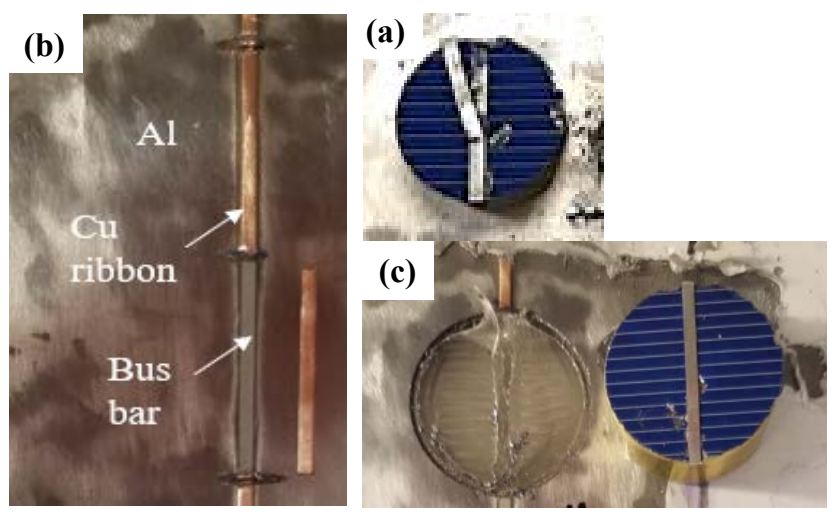

Fig. 5. (a) Cored cell with detached $\mathrm{Cu}$ ribbon after removal from the module; (b) Back of the module with cuts at locations to be cored; (c) Back of the module after coring and removal of cored sample. 


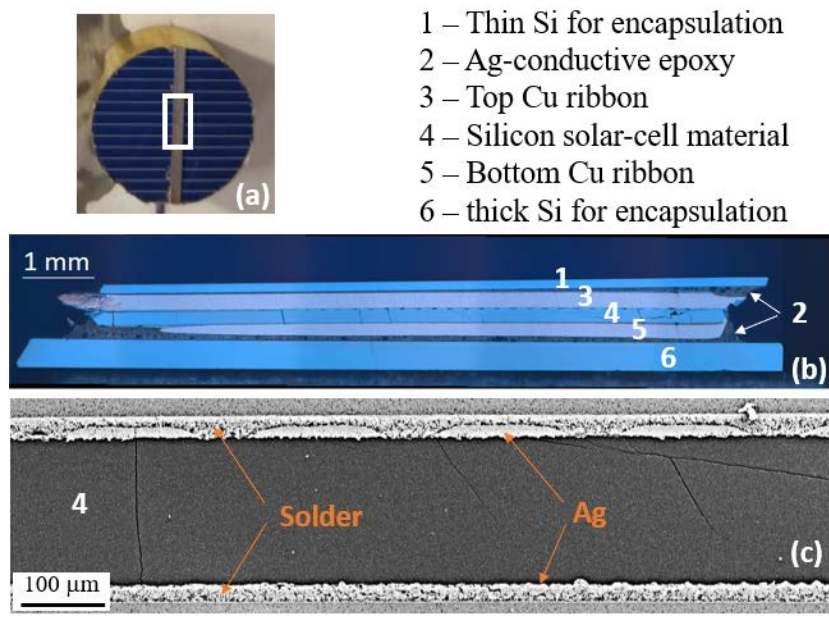

Fig. 6. (a) Silicon sample after coring. (b) Optical microscopy image showing the several layers of the cross section of the cored sample. (c) SEM image of the cross section showing the location of the $\mathrm{Ag}$ and solder layers. Cracks extending from the bottom to the top of the Si solar cell are clearly visible.

As mentioned before, the objective of coring this module was to analyze the cross section in the region around the solder location. For this purpose, we needed to protect the solder regions, including the ribbons, during sample preparation. This was accomplished by cutting the cored samples with pliers in the region close to the ribbon and encapsulating and polishing them. The polishing was stopped as soon as the ribbon and solder region were reached, as revealed by an optical microscope. The structure of such a sample is shown in Fig. 6, where we observe the region from where the sample was prepared (a) and the cross section showing the different layers. The cracks observed in the Si cell may or may not have been introduced during coring and are under investigation. The EDS analysis showed a significant amount of $\mathrm{Sn}$ in the $\mathrm{Ag}$ back and front contacts, compatible with the formation of $\mathrm{Ag}_{3} \mathrm{Sn}$, which has been shown to increase the series resistance of the module [7]. The initial findings of this work have been presented elsewhere [8].

\section{CONTACTS FOR EFFICIENCY-BASED MEASUREMENTS}

Finally, we describe a procedure to place small openings at different locations directly over the bus bars, to allow for the measurement of the cell parameters of individual cells on PV modules. For this purpose, we use a special bit installed on a Dremel tool that cuts down into the back of the PV module. Initially, we tried to control the size and depth of the cut by simply holding the Dremel tool, but it proved to be unreliable and often the bit would go deeper than desired. To avoid this problem, we use a special device to hold the drill exactly over the place where the opening will be made. At the same time, the device limits the depth that can be reached by the drill, so there is no damage of the module. The schematic of this procedure is shown in Fig. 7. Several openings were cut on many different locations of individual solar cells in the module described in the previous section. This allowed us to measure efficiency-related parameters of individual cells, as well as groups of cells, and to study how the power output varied at different locations of the module and how the degradation was distributed. These measurements can identify areas to be cored and allow for the correlation between microscopic and macroscopic properties measured on different locations of the module.

\section{CONCLUSIONS}

Due to differences in PV module design and analysis requirements, standard coring procedures must be constantly modified. In this work, we describe examples of modifications in our standard coring procedure that allowed us to core different types of modules. For instance, we were able to core HIT modules while preserving the thin ITO back contact, as well as areas with bus bars and $\mathrm{Cu}$ ribbons on standard $\mathrm{Si}$ modules to study the structure and composition of the solder regions. Finally, we described a simple procedure to allow for measuring efficiency-related parameters on individual cells and groups of cells in PV modules.

\section{ACKNOWLEDGMENT}

This work was authored by the Alliance for Sustainable Energy, LLC, the manager and operator of the National Renewable Energy Laboratory. The views expressed in the article do not necessarily represent the views of the DOE or the U.S. Government. The U.S. Government retains and the publisher, by accepting the article for publication, acknowledges that the U.S. Government retains a nonexclusive, paid-up, irrevocable, worldwide license to

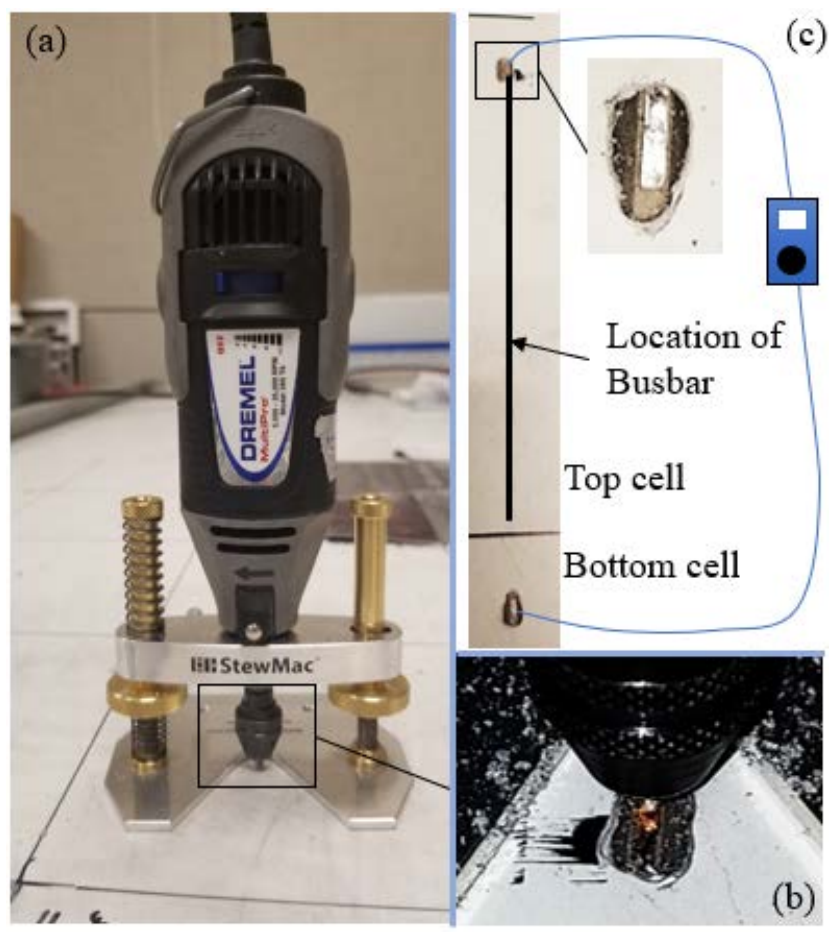

Fig. 7. (a) Configuration of the procedure to make openings on the back of PV modules. (b) Higher magnification showing the removed material. (c) Openings on the module and the measurement schematic. 
publish or reproduce the published form of this work, or allow others to do so, for U.S. Government purposes.

\section{REFERENCES}

[1] H.R. Moutinho, S. Johnston, B. To, C.-S. Jiang, C. Xiao, P. Hacke, J. Moseley, J. Tynan, N.G. Dhere, and M.M. Al-Jassim, "Development of coring procedures applied to $\mathrm{Si}, \mathrm{CdTe}$, and CIGS solar panels," Solar Energy 161 (2018) 235-241.

[2] H.R. Moutinho, B. To, C.-S. Jiang, C. Xiao, C.P. Muzzillo, P. Hacke, J. Moseley, J. Tynan, N.G. Dhere, L. Mansfield, M.M. AlJassim, and S. Johnston, Artifact-free coring procedures for removing samples from photovoltaic modules for microscopic analysis, Proc. World Conf. Photov. En. Conv. (Waikoloa, HI, 2018) p. 1313.

[3] P. Chakraborty, "Ultra-high depth resolution SIMS for the interfcace analysis of complex low-dimensional structure," Nucl. Instrum. Meth. Phys. Res. B 266 (2008) 1858.

[4] S.M.F. Zhang, D.B. Sulas-Kern, R. (Rob) L. Chin, A. Mahboubi Soufiani, D.C. Jordan, H.R. Moutinho, I. Perez-Wurfl, and Z. Hameiri, "Investigation of HIT module degradation: A post- mortem approach," To be presented at the $47^{\text {th }}$ IEEE Photov. Spec. Conf. (June 15-August 21). Virtual meeting.

[5] D.B. Sulas-Kern, S. Johnston, and J. Meydbray, "Fill factor loss in fielded photovoltaic modules due to metallization failures, characterized by luminescence and thermal imaging," 2019 IEEE $46^{\text {th }}$ Photovoltaic Specialists Conference (PVSC), Chicago, IL, USA, 2019, pp. 2008-2012, doi: 10.1109/PVSC40753.2019.8980840.

[6] https:/www.scienceabc.com/eyeopeners/tempered-laminatedcar-windshield-glass-why-break-such-small-pieces.html

[7] T.L. Yang, K.Y. Huang S. Yang, H.H. Hsieh, and C.R. Kao, "Growth kinetics of $\mathrm{Ag}_{3} \mathrm{Sn}$ in silicon solar cells with a sintered Ag metallization layer," Sol. En. Mater. Sol. Cells 123 (2014) 139.

[8] D.B. Sulas-Kern, S. Johnston, D.C. Jordan, H. Moutinho, M. Young, J. Meydbray, C.S. Jiang, M. Al-Jassim, A. Norman, M.A. Alam, R. Asadpour, M. Owen-Bellini, K. Terwilliger, A. Sinha, L. Schelhas, R. Bhoopathy, S. Zhang, and Z. Hamieri "Degradation mechanisms in fielded modules: Imaging for identification of resistance effects," presented at the Photovoltaic Reliability Workshop (PVRW), Lakewood, CO, USA, 2020. 